\title{
O PAPEL DAS CIDADES COMO ATORES DA GOVERNANÇA AMBIENTAL GLOBAL
}

\section{Resumo.}

\section{Jorge Jurado* Alcindo Gonçalves ${ }^{* *}$}

$\mathrm{O}$ artigo apresenta a ideia das cidades como novos atores da governança ambiental global (GAG). O objetivo é o estudo e análise do papel das cidades na abordagem das questões ambientais globais. O método de pesquisa foi o teórico-dedutivo, partindo do entendimento da GAG, analisando a organização destas, assim como soluções locais aos problemas ambientais de relevância global. Se revisaram instrumentos internacionais, bibliografia nacional e estrangeira e planos de ação ambientais de cidades. Como conclusão se confirma o papel destacado das cidades na temática ambiental e a existência de redes de política e paradiplomacia para abordar questões ambientais.

Palavras-chave: Governança Ambiental Global; Cidades; Paradiplomacia; Direito Ambiental Internacional; Mudanças Climáticas.

\section{THE ROLE OF CITIES AS ACTORS OF GLOBAL ENVIRONMENTAL GOVERNANCE}

\begin{abstract}
Article presents idea that cities like new actors in global environmental governance (GEG). The main objective is study and analysis of the role that cities play in addressing global environmental issues. The research method was theoretical-deductive, because it began by understanding the concept of GEG to later analyze the organization of cities and examples of local solutions for environmental problems of global relevance. The research involved the study of international instruments, national and foreign bibliography and action environmental plans. Some research findings confirm the prominent role of cities in environmental issues and the existence of policy networks addressing environmental issues.
\end{abstract}

Key words: Global Environmental Governance; Cities; Paradiplomacia; International Environmental Law; Climate Change.

\section{Introdução.}

A governança tem sua origem em ações de entidades multilaterais como o Banco Mundial e o Fundo Monetário Internacional ao final da década dos anos 1980 quando elas

\footnotetext{
* Advogado Universidade Santo Tomás. Mestre Direito dos Recursos Naturais Universidade Externado da Colômbia. Doutorando Direito Ambiental Internacional Universidade Católica de Santos. Bolsista Programa Estudantes-Convênio de Pós-Graduação - PEC-PG, do CNPq - Brasil. jorgeluis_jurado@ hotmail.com

** Doutor em Ciência Política pela FFLCHUSP. Professor e coordenador do Programa de Pós-Graduação Stricto Sensu (Mestrado e Doutorado) em Direito da Universidade Católica de Santos. alcindo@unisantos.br
} 
buscavam impor a "boa governança" como uma estratégia composta por princípios cuja função era guiar seu trabalho e as interações com os países membros (GONÇALVES e COSTA, 2011 p. 21-24).

Este conceito de governança estava baseado em uma visão liberal do mercado e centrado no papel do Estado e sua forma de organização e desenvolvimento no espaço de poder, especialmente na atuação dos órgãos nacionais frente aos regionais e mesmo locais, que implicava uma desconcentração de responsabilidades, incumbência de recursos para o fornecimento de serviços e infraestrutura, assim como a delegação de autoridade administrativa através de diferentes funções (GONÇALVES e COSTA, 2011 p. 21-24.)

Posteriormente, conforme a Comissão sobre Governança Global (CGG), formada pela Organização das Nações Unidas (ONU) no início dos anos 1990, a concepção foi alterada e governança passou a ser entendida como a soma de muitas maneiras pelas quais indivíduos e instituições, públicos e privados, gerenciam seus assuntos comuns, com o qual esse processo engloba uma ampla gama de atores além dos Estados (O'BRIEN et al, 2000 p. 2). Trata-se assim de um processo contínuo que permite acomodar interesses conflitantes e realizar ações cooperativas (COMISSÃO SOBRE GOVERNANÇA GLOBAL, 1996, p. 2)

Neste sentido, quando se fala de governança global, deve-se entender que esse conceito abrange novos olhares que permitem incluir outros atores na tomada de decisões que envolvem diferentes problemas comuns no cenário internacional, como acontece com as ONG's, governos subnacionais, empresas multinacionais, cidades e sociedade civil, entre outros.

Desta forma, a governança global é um modelo de articulação e cooperação entre atores sociais e políticos e os arranjos institucionais (SANTOS, 1997 apud REI e GRANZIERA, 2015 p. 149), cuja finalidade, como acima mencionado, é obter soluções para as diferentes problemáticas que atingem a comunidade global em geral, desenvolvidas em ambiente de consenso e não imposição.

Assim, um dos melhores exemplos de problemas globais comuns sobre os quais vale a pena a estruturação de um sistema de governança é o relativo às questões ambientais, já que da boa saúde do meio ambiente mundial dependem não só a subsistência dos países mas também a sobrevivência das diferentes espécies de seres vivos, incluído o homem, sendo especialmente relevantes em face das denominadas mudanças climáticas, cuja existência e avanço fazem necessária a adoção de estratégias articuladas para seu combate e adaptação. 
Nesse contexto, as cidades começam a desenvolver maior e importante participação nas discussões ambientais globais, já que hoje sua dinâmica de crescimento e expansão implica em crescente consumo de energia em meios de transporte baseados em combustíveis de origem fóssil $^{1}$ e consequente geração de grande parte dos gases de efeito estufa (GEE) mundiais $^{2}$, que contribuem na intensificação de fenômenos naturais, que sem dúvida alguma impactarão negativamente no espaço urbano e na qualidade de vida e saúde dos cidadãos.

A importância atual das cidades é tão grande, que Beck (2016, p. 206) manifesta que, apesar destas continuar como atores secundários no quadro nacional e internacional, em razão do que ele denomina a metamorfose do mundo ${ }^{3}$ a relação entre os Estados e as cidades inverte-se, apontando que, por meio dos riscos globais ambientais, elas podem estar mais abertas a políticas cosmopolitas de cooperação.

Essa colocação corresponde diretamente aos objetivos da governança global, fazendo que as atividades desenvolvidas pelas cidades para combater as mudanças climáticas possam ser o ponto de inflexão para que se possa começar a obter melhores resultados que os alcançados até agora sob o tradicional quadro de relações internacionais dos Estados nacionais.

Por isso, o mesmo autor acima citado estabelece que, devido ao fracasso das tradicionais conferências internacionais, a fim de encontrar respostas para as alterações climáticas, é necessário não só olhar paras as Nações Unidas, senão também para as Cidades Unidas (2016, p. 63), deixando vislumbrar que as problemáticas globais, neste caso ambientais, podem ser atingidas de melhor forma por meio das ações locais das cidades.

Pelas razões expostas, o objetivo principal do presente artigo é estudar e analisar o papel que na atualidade desempenham as cidades ao abordar as questões ambientais globais. Nesse sentido, são revisadas as diferentes formas de organização pelas quais este novo ator consegue

\footnotetext{
${ }^{1}$ Sobre a contribuição das cidades na emissão de GEE, Satterthwaite (2008 p. 542) aponta que, embora elas tenham alguma responsabilidade, é importante não confundir a percentagem de emissores de $\mathrm{CO}_{2}$ com a totalidade de emissores de GEE, já que 75 ou $80 \%$ de participação na produção de dióxido de carbono corresponderiam só a um 30 ou $40 \%$ das emissões totais de GEE no mundo.

${ }^{2}$ Segundo dados da ONU, as cidades são responsáveis pelo $75 \%$ das emissões dióxido de carbono $\left(\mathrm{CO}_{2}\right)$ no mundo. Cfr. ONU AMBIENTE. Cities and climate change. Disponível em: https://www.unenvironment.org/explore-topics/resource-efficiency/what-we-do/cities/cities-and-climatechange> Acesso em: 20 mai. 2019.

${ }^{3}$ Quando Beck (2016, p. 15) explica a diferença entre os conceitos de mudança, evolução, revolução e transformação de uma parte, do que ele denomina metamorfose, aponta o seguinte: "A metamorfose implica uma transformação muito mais radical, na qual as velhas certezas da sociedade moderna desaparecem, e algo novo emerge. Para compreender esta metamorfose do mundo, é necessário explorar os novos começos, concentrarmonos naquilo que está a emergir a partir do antigo e tentar perceber estruturas e normas futuras na convulsão do presente."
} 
expor suas posições no cenário internacional e algumas das respostas que as mesmas estão fornecendo para atingir essas problemáticas ambientais.

O método de pesquisa para a elaboração do artigo foi o teórico-dedutivo, e seu desenvolvimento começou pelo entendimento do conceito de governança ambiental global, aspecto que será objeto de abordagem no primeiro item do artigo, para, posteriormente, serem analisadas as formas de organização das cidades no contexto internacional, sua ampla participação nas discussões mundiais relacionadas com o meio ambiente, assim como exemplos de soluções locais aos problemas ambientais cujo impacto é de relevância global, tópicos que vão ser desenvolvidos nos itens segundo e terceiro, respectivamente.

Nesse sentido, a pesquisa implicou revisar diferentes instrumentos internacionais de relevância em matéria ambiental, assim como seu processo de elaboração, e realizar uma análise crítica de bibliografia de doutrinadores nacionais e estrangeiros, como de informações contidas em sítios web sobre a matéria que puderem fornecer maiores dados de importância para o encaminhamento do artigo.

\section{Governança ambiental global.}

As questões ambientais, tendo em vista sua natureza e ligação direta com a totalidade de nações e Estados do mundo, criam um cenário de interdependência entre os principais sujeitos do direito internacional (Estados e organizações internacionais), razão pela elas constituem bom exemplo no qual vale a pena construir um sistema de governança global nos moldes estabelecidos pela CGG, muito mais abrangente e com participação de novos atores em procura das soluções comuns para os desafios que representem o equilíbrio ambiental do planeta.

A mesma CGG, em seu relatório do ano 1995, identifica a existência de uma mudança ambiental produto do crescimento demográfico e a expansão da atividade econômica, motivo pelo qual sua gestão com vistas a proteger os interesses das gerações futuras é reconhecida como uma questão de suprema importância (COMISSÃO SOBRE GOVERNANÇA GLOBAL, 1996, p. 21-23).

Nesse sentido, a CGG menciona o impacto que as pessoas exercem sobre os recursos vitais do planeta, os quais ameaçam tornar a Terra menos habitável e a vida mais perigosa, sendo possível acumulá-los em: a) solos que perdem a fertilidade ou são destruídos pela erosão; b) pastagens com excesso de rebanhos; c) desertificação; d) redução de pesqueiros; e) 
espécies em extinção; f) desmatamento; g) poluição do ar e da água; h) as mudanças climáticas e i) o esgotamento da camada de ozônio (COMISSÃO SOBRE GOVERNANÇA GLOBAL, 1996, p. 21-23).

Desta forma, em resposta às problemáticas ambientais globais identificadas, a procura de soluções requeria necessariamente uma abordagem igualmente global que envolvesse visões diferentes além das originadas pelos Estados e pelas organizações internacionais, de forma a desenvolver o conceito da governança global em matéria ambiental, denominada Governança Ambiental Global (GAG).

Segundo Speth (2005, p. 19-24), uma consequência derivada das preocupações internacionais em relação ao meio ambiente foi a profusão de conferências, negociações, planos de ação, tratados e outras iniciativas de caráter internacional, cujo desenvolvimento esteve baseado em vasta produção de pesquisas cientificas e de análises políticas

De outra parte, o mesmo autor identifica, como um dos origens da GAG, a legitimação nos Estados Unidos das preocupações ambientais, as quais, embora mais restritas aos aspectos domésticos, permitiram que as questões ambientais ganhassem força tanto em nível local como em escala global com o surgimento de inúmeros trabalhos científicos relacionados com o impacto das atividades humanas no meio ambiente (SPETH, 2005, p. 19-24).

Na década do anos 1970 começou a se formar, no cenário internacional, a arquitetura da institucionalidade ambiental, já que, como resultado da Conferência das Nações Unidas sobre o Meio Ambiente de 1972, se constituiu o Programa das Nações Unidas sobre o Meio Ambiente (PNUMA), o qual, embora para alguns autores precise hoje de revisão e reestruturação, é considerado como a âncora internacional do meio ambiente (IVANOVA, 2009), colocação que é compartilhada pela sua importância no desenvolvimento da função de coordenação das políticas ambientais globais e portanto protagonista da atual GAG.

A criação do PNUMA não é suficiente para que se possa relacioná-la com a governança, já que a maioria dos elementos constituintes desta faltariam, mas seu nascimento e evolução sem dúvida permitiram uma melhor formação e materialização do conceito.

Por exemplo, a sustentação técnica, que já contava com antecedentes como o Clube de Roma ${ }^{4}$, após estruturação do PNUMA teve reforço importante na sua consolidação, como são

\footnotetext{
${ }^{4}$ Até 1969, o Clube foi deliberadamente administrado como uma "não-organização", um grupo informal de indivíduos que se reuniam frequentemente para entender melhor os problemas globais. No entanto, à medida que seu número se expandiu, tornou-se necessário criar uma estrutura legal que deu como resultado a realização em 1970 da primeira reunião oficial do Clube de Roma na qual se criou uma comissão de pesquisadores cujo
} 
o chamado relatório Brundtland estruturado pela Comissão Mundial sobre Meio Ambiente e Desenvolvimento em 1987 e a posterior constituição em 1988 do Painel Intergovernamental sobre Mudanças Climáticas (IPCC) ${ }^{5}$.

Talvez uma das mais importantes diferenças entre o trabalho desenvolvido pelo Clube de Roma e a Comissão Brundtland, que pode ser entendida como um primeiro passo na vinculação de novos atores na GAG, foi a metodologia usada.

Enquanto o Clube de Roma partiu, para a elaboração do relatório "Os Limites do Crescimento", de um método matemático, científico, formal e escrito misturando as informações já produzidas e novas ferramentas de processamento de dados como o computador (MEADOWS et al, 1972, p. 21-24), a Comissão fez um trabalho fora dos escritórios tentando um confronto entre os dados técnicos e a realidade das regiões, especialmente em desenvolvimento (ONU, 1987, p. 10-15).

Esta diferença permitiu abordagem diferenciada e mais próxima da sociedade civil e de atores como as cidades e os governos subnacionais, sem que isso signifique em forma alguma um desconhecimento pelo trabalho técnico desenvolvido com antecedência pelo Clube de Roma.

Observe-se como a estrutura "burocrática" representada pelo PNUMA começa ser acompanhada por outros atores que em conjunto fazem parte do que hoje se conhece como GAG. Trata-se assim de incluir cientistas cujas pesquisas e abordagens em matéria ambiental conformam a base teórica e conceitual das políticas ambientais elaboradas no cenário internacional no quadro da Organização das Nações Unidas (ONU).

Anos depois teve lugar a Conferência das Nações Unidas sobre o Meio Ambiente e o Desenvolvimento, também conhecida como Eco-92, da qual surgiram além de textos de convenções multilaterais como a Convenção de Diversidade Biológica e Convenção-Quadro das Nações Unidas sobre Mudança do Clima, um plano de ação global denominado Agenda $21^{6}$, documento soft law de importância maiúscula na GAG, já que sua natureza de direito

objetivo era elaborar o primeiro relatório. Cfr. THE CLUB OF ROME. About us. Disponível em: <https://www.clubofrome.org/about-us/history/> Acesso em: 10 jun. 2019.

5 "O objetivo do IPCC é fornecer aos governos, em todos os níveis, informações científicas que possam ser usadas para desenvolver políticas climáticas. Os relatórios do IPCC também são um insumo fundamental para as negociações internacionais sobre mudanças climáticas." Cfr. IPCC. About the IPCC. Disponível em: <https://www.ipcc.ch/about/> Acesso em: 10 jun. 2019.

6 "A Agenda 21 pode ser definida como um instrumento de planejamento para a construção de sociedades sustentáveis, em diferentes bases geográficas, que concilia métodos de proteção ambiental, justiça social e 
flexível não obrigatório ${ }^{7}$, mas capaz de influenciar a vontade e ações dos Estados, deixa ver um novo paradigma na forma de abordar as questões ambientais, baseado em planos de longo prazo e metas flexíveis mas monitoráveis pelos Estados e demais atores da GAG.

Em relação à questão da soft law, Beyerlin e Marauhn (2011, p. 289-291), em estudo sobre a soft law ambiental internacional, manifestam que, embora sua origem seja não-legal, ela compartilha com as normas denominadas hard law sua qualidade normativa, entendida como a capacidade de direcionar direta ou indiretamente a conduta do seus destinatários, sendo esta um requisito da norma soft law para se diferenciar dos ideais políticos ou morais.

Neste sentido, é claro que normas deste tipo fazem parte da GAG, já que são planos de ação que procuram soluções aos problemas ambientais, estabelecendo metas e calendários verificáveis pelos atores internacionais, sem que dessa verificação seja possível esperar a imposição de sanções, porque o foco da GAG fica mais próximo do princípio de cooperação, a participação ampliada de atores e do consenso (REI e GRANZIERA, 2015, p. 155) que das atividades sancionatórias para obter os resultados planejados.

Essa participação ampliada de atores, que é caraterística própria da GAG, teve protagonismo importante na Conferência das Nações Unidas sobre Desenvolvimento Sustentável de 2012 (RIO+20), na qual se criaram espaços de diálogo para a sociedade civil, como foram os "Diálogos para o Desenvolvimento Sustentável" e a "Cúpula dos Povos", assim como para as cidades como ator da GAG através do encontro da rede internacional C40 “Cities Climate Leadership Group” (LORENZETTI e CARRION, 2012, p. 726-727).

Em 2015, dois fatos reforçaram o conceito de GAG. Em primeiro lugar, houve a aprovação da Agenda 2030, plano de ação de longo prazo discutido e negociado durante anos, no qual os países que aderiram propõem dezessete objetivos, com a finalidade de que o desenvolvimento a escala global esteja baseado em uma relação equilibrada entre as dimensões econômica, social e ambiental para que o mesmo seja sustentável (ONU, 2015), motivo pelo qual estas metas foram chamadas como Objetivos de Desenvolvimento Sustentável (ODS).

Embora seja possível afirmar que todos os ODS estão relacionados com questões ambientais, alguns deles destacam-se por ter uma relação mais direta com as mesmas, como

eficiência econômica" Cfr. MINISTÉRIO DO MEIO AMBIENTE DO BRASIL. Agenda 21. Disponível em: <http://www.mma.gov.br/responsabilidade-socioambiental/agenda-21>Acesso em: 10 jun. 2019.

7 As agendas e planos de ação são classificados por Nasser (2006. p. 117-140) como um exemplo de “Instrumentos Concertados Não Obrigatórios Criados Pelos Estados", os quais, embora concertados, não são tratados e em princípio não criam obrigações jurídicas. 
os seguintes: a) ODS 2: Fome zero e agricultura sustentável; b) ODS 6: Água potável e saneamento; c) ODS 7: Energia limpa e acessível; d) ODS 11: Cidades e comunidades sustentáveis; e) ODS 12: Consumo e produção responsável; f) ODS 13: Ação contra a mudança global do clima; g) ODS 14: Vida na água; h) ODS 15: Vida terrestre (ONU, 2015).

Neste ponto, vale a pena indicar que a elaboração de agendas como estratégia de abordagem dos problemas ambientais globais na procura de soluções comuns é a base estrutural da GAG, já que, por tratar-se de cronogramas de atuação dos Estados com ações de longo prazo, permitem superar algumas dificuldades derivadas das tradicionais respostas geradas desde o Direito Internacional do Meio Ambiente, no qual, segundo Rei (2018, p. 137138), os interesses dos Estados em razão do horizonte de curto prazo e a natureza políticoeconômica impediam reações de forma adequada.

O segundo fato que aconteceu em 2015 foi a assinatura do Acordo de Paris ${ }^{8}$. Como apontam Rei, Gonçalves e Souza (2017, p. 93), houve importante inovação para estabelecer as metas de redução das emissões de GEE, deixando do lado a lógica do Protocolo de Quioto ${ }^{9}$ e avançando na configuração de compromissos de redução autoassumidos voluntariamente pelas partes que, se descumpridos, poderiam ser cobrados pelos demais envolvidos, não apenas com sanções, mas com a possibilidade de ações e intervenções, seguindo uma estratégia de bottom-up.

Em suma, para Gonçalves e Costa (2011 p. 89-90) a construção da GAG visa fundamentalmente permitir que a cooperação e consenso sejam alcançados na negociação para resolver os diferentes problemas ambientais e propõem um roteiro para a obtenção de níveis satisfatórios, o qual inclui: a) a percepção dos problemas ambientais; b) um diagnóstico e estudos técnico-científicos que permitam o planejamento de soluções; c) o envolvimento de

\footnotetext{
${ }^{8}$ Trata-se de um acordo multilateral assinado pelas partes da Convenção Quadro das Nações Unidas sobre a Mudança do Clima durante a reunião 21 da conferência das partes realizada em 2012. Com o acordo os diferentes países reforçaram a resposta mundial frente às mudanças climáticas, estabelecendo como meta basilar de longo prazo, manter o aumento da temperatura mundial sob os dois graus centrígrados, assim como alcançar um ponto máximo de emissões de GEE, aumentar a conservação dos sumidouros de GEE e a capacidade de adaptação e mitigação às mudanças climáticas e a possibilidade das partes para fazer contribuições voluntarias na mitigação das emissões de GEE. Cfr. UNFCCC. ¿Qué es el Acuerdo de París? Disponível em: $<\mathrm{https} / / /$ unfccc.int/es/process-and-meetings/the-paris-agreement/que-es-el-acuerdo-de-paris> Acesso em: 18 set. 2019.

${ }_{9}^{9}$ Protocolo da Convenção Quadro das Nações Unidas sobre a Mudança do Clima assinado em 1997 com a finalidade de estabelecer o compromisso dos países desenvolvidos de reduzir o total das emissões de GEE tomando como base pelo menos um 5\% dos níveis de emissões de 1990, meta que deveria ser atingida para o período compreendido entre os anos 2008 até 2012 (artigo 3). O protocolo igualmente estabelecia a possibilidade dos países sem obrigações de redução de emissões de adiantar ações com essa finalidade, tão como acontece com os mecanismos de desenvolvimento limpo (MDL) (artigo 12). (ONU, 1998).
} 
múltiplos atores no processo de discussão e formulação de soluções; e) a articulação dos diferentes interesses e construção de mecanismos de cooperação entre os Estados nacionais e a sociedade civil.

A GAG não é, porém, um processo acabado. Ao contrário, está em constante evolução e é objeto de profundas discussões quanto a seu futuro, tanto que autores como Esty e Ivanova (2005, p. 258-265) destacam pelo menos quatro alternativas básicas em face da GAG:

a) Não fazer nada, a qual teria sentido sempre que os custos de uma ação de governança fossem maiores que os benefícios previstos;

b) Aprimorar o status quo, que significa revitalizar o sistema existente e centralizá-lo no PNUMA, deixando ver as prováveis dificuldades de uma mudança mais ampla;

c) Criar uma nova organização global do meio ambiente, pensada sob a conclusão de que a arquitetura ambiental em escala planetária que hoje existe é pouco prática;

d) Desenvolver um mecanismo global do meio ambiente, baseado na criação de uma estrutura capaz de realizar funções necessárias em nível planetário a qual deve ser levantada desde o conhecimento especializado e as relações entre os governos, o setor privado, as ONG's e as redes globais de política pública.

\section{As cidades como novos atores da governança ambiental global.}

Como afirmado no item anterior, um sistema de governança global implica a participação no processo internacional de tomada de decisões de novos atores além dos tradicionais Estados nacionais e das organizações internacionais, motivo pelo qual apareceram as cidades e seus governos nas diferentes discussões relativas às problemáticas globais.

Para Barbi (2015, p. 79), a importância das cidades e seus governos locais em matéria de sustentabilidade global remonta ao Relatório Brundtland de 1987 e tem maior ênfase na Conferência do Rio de 1992 quando se utilizou o mote "pensar globalmente, agir localmente". A mesma autora relata como Jeb Brugmann, que atuava como secretário geral da rede conhecida como ICLEI (Governos Locais pela Sustentabilidade), ajudou para que essa perspectiva fosse incluída e além disso para que fosse criado o capítulo 28 da Agenda 21 (Bulkeley \& Betsill, 2003 apud BARBI, 2015, p. 79).

O mencionado capítulo 28 leva por título "Iniciativas das Autoridades Locais em Apoio à Agenda 21" e estabelece com clareza que a participação dessas autoridades são um fator 
importante no cumprimento dos objetivo da Agenda 21 porquanto elas estão encarregadas da criação, funcionamento e manutenção da infraestrutura econômica, social e ecológica, além de supervisionar o planejamento através de políticas e regulamentações ecológicas locais que contribuem na execução das políticas ambientais nacionais e subnacionais (ONU, 1992).

Pode-se observar que esse novo olhar incluído na Agenda 21 transformou de algum modo a forma de entender as atividades de governança, permitindo a participação daqueles atores que têm maior possibilidade de adiantar as diferentes atividades de planejamento do território e consequente implantação de políticas ambientais efetivas e benéficas não só para as pessoas que moram nos perímetros locais senão para os diferentes conglomerados sociais presentes em cenários regionais, nacionais e globais.

Nesse sentido, Schmidt e Guerra (2010, p. 110) reconhecem na Agenda 21 uma caraterística de transversalidade em termos setoriais como de participantes, sendo essa sua marca mais próxima do que geralmente é denominado como governança "glocal”, ou seja, aquela processada num contexto de negociação que ultrapassa aos representantes dos EstadosNação.

Em face das mudanças climáticas, autoras como Macedo e Setzer (2015, p. 75-85) identificam igualmente crescente protagonismo das cidades na arena internacional de políticas e medidas de mitigação e adaptação às mudanças climáticas, consequência do aumento da população que mora nas áreas urbanas, com importante participação destas na produção de GEE e dos impactos negativos que as populações agrupadas nestas áreas sofrerão com o passar do tempo.

Nessa perspectiva, o conteúdo da Agenda 2030, citada acima, com certeza exemplifica a importância das cidades na GAG, porquanto dedica dois ODS, os números 11 e 13, às diferentes atividades que a partir das cidades devem-se realizar para tornar os espaços urbanos lugares inclusivos, seguros, resilientes e sustentáveis, assim como cenários de implementação positiva de medidas de mitigação e adaptação aos desafios que representam as mudanças climáticas na atualidade (ONU, 2015 p. 30).

Essa ligação entre os ODS acima mencionados resulta além de evidente muito interessante, porque deixa ver como o bom sucesso de um deles depende diretamente do bom desenvolvimento do outro. Veja-se, por exemplo, como a meta "b" do ODS11 procura aumentar substancialmente até 2030 o número de cidades com planejamento e implementação de políticas frente às mudanças climáticas (ONU, 2015 p. 30) e por sua parte a meta "b" do 
ODS13 menciona expressamente a promoção de mecanismos para criar capacidades para o planejamento relacionado com as mudanças climáticas com um foco especial, entre outras coisas, nas comunidades locais (ONU, 2015 p. 32).

Em conformidade, Martins e Ferreira (2011, p. 622-623) acreditam que as cidades e os governos locais são fundamentais na hora de considerar e planejar as ações de adaptação e mitigação às mudanças climáticas, porque consideram que as mesmas podem lidar de forma mais eficiente com a infraestrutura urbana e serviços públicos essenciais para o bem-estar das pessoas, assim como para regular e controlar as ações dos indivíduos e as empresas no nível local (SATTERTHWAITE, et al, 2007 apud MARTINS e FERREIRA, 2011, p. 622-623).

Constata-se que as cidades e os governos locais têm papel importante e principal no interior da denominada GAG, sendo que seu desenvolvimento depende em grande parte dos bons resultados no cumprimento dos diferentes objetivos ambientais das diferentes agendas sobre a matéria, situação que permite afirmar que, hoje em dia, esse sistema de governança global apresenta desafios de natureza multinível que devem ser atingidos de forma integral e especialmente seguindo o desenvolvimento do que a doutrina reconhece como estratégia bottom-up, na qual estes novos atores da GAG são fundamentais.

Apesar da importância atual das cidades e os governos locais na GAG, deve-se entender que isso não significa que, antes dos antecedentes acima estudados, esses atores não existiam. Sua participação era, porém, limitada, principalmente pelo papel que desenvolviam os Estados nacionais e as organizações internacionais, e com certeza porque não contavam eles com uma adequada organização que lhes permitisse uma maior visibilidade na hora de participar das discussões globais sobre o meio ambiente, situação que começou mudar a finais da década de 1980, tal como será estudado no seguinte subitem.

\subsection{Organização das cidades para a atuação internacional.}

Um dos principais problemas identificados no tradicional sistema de relações internacionais é sua falta de efetividade em razão da burocracia e hierarquização que o mesmo apresenta, circunstâncias que implicam muitas vezes na resposta tardia dos sujeitos do direito internacional aos problemas globais, que necessitam, na maioria de casos, de respostas rápidas e eficazes, tal como acontece com a temática ambiental.

Efetivamente, alguns autores identificam, como problema da governança tradicional, a falta de conhecimento e flexibilidade para atender em devida forma aqueles desafios complexos e cambiantes que representam hoje em dia as problemáticas globais, motivo pelo 
qual observam o surgimento das redes globais como alternativa ao sistema de governança global (STRECK, 2005 p. 140-142) ou como componente da mesma para a superação das brechas existentes entre necessidades e resultados nos sistemas de governança, incluída a GAG (SETTE, 2010 p. 52).

Dessa forma, as redes podem ser entendidas como um novo arranjo organizacional e modelo de gestão de políticas ou de governança que envolve tanto o nível global como o local (SETTE, 2010 p. 56), formadas geralmente em torno de questões internacionais e minimizando as hierarquias em razão da participação de vários setores, possibilitando assim maiores recursos e as sinergias e respostas mais eficientes (STRECK, 2005 p. 140-142).

Consoante com o anterior e tendo verificado que as problemáticas ambientais, tanto desde o ponto de vista negativo como desde o olhar da implantação de medidas de mitigação e adaptação aos desafios das mesmas, estão ligadas fortemente às atividades de planejamento e gestão das cidades, não resulta estranho afirmar que esse cenário é apropriado para a conformação de redes de cidades focadas nos temas ambientais.

Bem coloca Beck (2016, p. 63) que, devido à decadência do Estado-nação, as cidades chegaram para se tornar agentes importantes na tomada de decisões coletivamente vinculativas, porque são nestas que as alterações climáticas produzem efeitos visíveis e portanto impulsionam inovação, cooperação e concorrência que ultrapassam as fronteiras. Por isso, o mesmo autor indica que as cidades podem ser hoje juridicamente redefinidas como agentes transnacionais e vozes organizadas da politica internacional.

Essa colocação de Beck é tão certa que na atualidade é possível falar em termos de paradiplomacia para se referir à organização e atuação internacional de governos diferentes aos nacionais, como seriam os regionais, subnacionais e com certeza os locais, produto da própria necessidade de representação e resolução dinâmica de controvérsias (KOTZIAS e SILVEIRA, 2015 p. 18).

Portanto, a paradiplomacia pode ser entendida como uma visão moderna das relações internacionais que abrange e permite a participação de atores diferentes aos tradicionais sujeitos do direito internacional (Estados-nação e organizações internacionais), motivo pelo qual atores como Brigagão (2005, p. 40 apud KOTZIAS e SILVEIRA, 2015 p. 18) a definem como um fenômeno presente nos diferentes países, sendo ou não Estados federais, que se caracteriza com a possibilidade de que Estados-membros, províncias, regiões e cidades adiantem sua própria política externa sem auxílio do governo central. 
Conforme exposto e focando o estudo nas formas de organização das cidades, Barbi (2015, p. 85-87) destaca a existência de pelo menos oito diferentes redes transnacionais de cidades focadas em atingir diferentes objetivos ambientais, que agrupam ao redor de 1.600 cidades em quase 140 países. As redes referidas pela autora são: a) Asian Cities Climate Change Resilience Network (ACCRN); b) C40 Climate Leadership Group; c) Climate Alliance; d) Energy Cities; e) ICLEI - Governos Locais pela Sustentabilidade; f) Metropolis; g) United Cities and Local Governments (UCLG); h) World Mayors Council on Climate Change (WMCCC) (BARBI, 2015 p. 85-87).

O ICLEI, por exemplo, é uma rede global de mais de 1.750 governos locais e regionais cuja origem está no redor de 100 diferentes países, sendo seu objetivo principal a implantação local de políticas de desenvolvimento sustentável de baixa emissão de GEE, fazendo desta forma que a sustentabilidade seja parte integral do desenvolvimento sustentável ${ }^{10}$ (ICLEI, 2019).

Já o C40 Cities é uma rede de grandes cidades do mundo comprometidas em lidar com as mudanças climáticas através de ações de cooperação e compartilhamento de conhecimento. Agrupa 94 megacidades que representam ao redor de 700 milhões de cidadãos e um quarto da economia global ${ }^{11}$.

Neste ponto vale a pena perguntar-se qual seria o beneficio, impacto ou efetividade para o meio ambiente derivado da participação das cidades deste tipo de redes. Pois bem, no caso de São Paulo está documentado que sua participação neste tipo de redes permitiu a promoção da agenda climática da cidade, a promulgação de sua política de mudança climática em 2009 e seu posicionamento como cidade líder em matéria ambiental (SETZER, 2009, 2013 apud MACEDO e SETZER2015, p. 75-85).

Existem ainda outras redes transnacionais de cidades com objetivos ambientais, porém estão limitadas a determinados perímetros geográfico da Terra. Elas, contudo, também representam avanços importantes em matéria de atuação das cidades no cenário internacional e especificamente na GAG.

Exemplo do anterior é o "Plano de Autarcas para o Clima e Energia" lançado em 2018 na Europa com a finalidade de reunir os governos locais que voluntariamente estivessem comprometidos em alcançar as metas e objetivos climáticos da União Europeia (UE), sendo

10 Cfr. ICLEI. ICLEI - Local Governments for Sustainability. 2019. Disponível em: <https://www.iclei.org/en/About_ICLEI_2.html> Acesso em: 15 jun. 2019.

${ }^{11}$ Cfr. C40 CITIES. About C40. 2019. Disponível em: <https://www.c40.org/about> Acesso em: 15 jun. 2019. 
assim uma iniciativa bottom-up que hoje, segundo informações oficiais, agrupa quase 10.000 municípios e regiões de 57 diferentes países, alcançando assim um impacto sobre cerca de 326,7 milhões de cidadãos ${ }^{12}$.

A iniciativa anterior foi pensada no quadro da UE, mas em 2016 ocorreu uma aliança com "The Compact of Mayors", da qual nasceu "O Pacto de Autarcas Global para o Clima e Energia", sendo ele um dos maiores movimentos de governos locais comprometidos em superar os seus objetivos nacionais para o clima e energia através da abordagem da mitigação e adaptação às mudanças climáticas e o acesso universal a energia segura, limpa e de preço acessível $^{13}$.

Do mesmo modo, na América Latina e Caribe, uma rede de cidades tem como objetivo alcançar um desenvolvimento sustentável por meio da socialização do conhecimento, lições aprendidas e boas práticas, servindo de cenário de encontro entre os setores público e privado, além da sociedade civil e academia. Chamada "Rede de Cidades BID", nasceu como iniciativa do Banco Interamericano de Desenvolvimento (BID) e hoje agrupa ao redor de 160 cidades $^{14}$.

Como observado, as cidades hoje em dia estão conscientes do seu importante papel em matéria ambiental e organizadas e comprometidas em adiantar diversas atividades com a finalidade de cumprir com os diferentes objetivos e metas ambientais inclusive ultrapassando os mesmos. Elas fazem uso das redes de cidades e conseguem colocar suas prioridades nos debates internacionais sobre o meio ambiente.

Assim, essa estratégia de participação e cooperação das cidades é inovadora no interior da GAG, porque deixa ver como as iniciativas de ação ambiental iniciadas desde as localidades, ou seja, desde os territórios onde existem mais proximidades com as pessoas e onde os governos locais têm maiores e melhores formas de direcionar as diferentes condutas que contribuem de forma negativa nos dados estatísticos ambientais, podem ser muito mais proveitosas e eficientes, já que são implementadas no lugar certo onde mais afetações ambientais podem-se apresentar.

\footnotetext{
${ }^{12}$ Cfr. PACTO DE AUTARCAS. Iniciativa do Pacto. Disponível em: <https://www.pactodeautarcas.eu/aboutpt/cov-initative-pt/origin-dev-pt.html> Acesso em: 16 jun. 2019.

${ }^{13}$ Cfr. GLOBAL COVENANT OF MAYORS FOR CLIMATE \& ENERGY. The history of the merger and the founding partners. 2019. Disponível em: <https://www.globalcovenantofmayors.org/about/> Acesso em: 16 jun. 2019.

${ }^{14}$ Cfr. BID. Red de Ciudades BID. 2019. Disponível em: <https://www.iadb.org/es/desarrollo-urbano-yvivienda/red-de-ciudades-bid> Acesso em: 16 jun. 2019.
} 
Enfim, as cidades jogam na atualidade um papel vital na GAG, motivo pelo qual suas atividades merecem estudo e monitoramento constante por parte dos outros atores, a fim de garantir bons níveis de cumprimento dos objetivos ambientais e portanto conseguir a melhoria na qualidade de vida das pessoas e nos indicadores ambientais globais. Isso decorre diretamente da grande participação que têm as cidades em relação aos diferentes fenômenos climáticos atuais.

\section{Ações locais das cidades como resposta às questões ambientais globais.}

Estudado o papel das cidades como atores da GAG e a forma pela qual elas se organizam para atuar nas discussões internacionais sobre o meio ambiente, resulta interessante analisar alguns exemplos de iniciativas locais adiantadas por algumas cidades que, sem dúvida, podem ser reconhecidas como ações "glocais", devido a seu impacto na melhoria do meio ambiente global, em razão da já mencionada interdependência existente entre os sistemas ambientais das cidades e o sistema ambiental global.

Assim, houve algumas medidas tomadas por parte de cidades em face das mudanças climáticas por meio das quais se desenvolvem diferentes mecanismos e constroem acordos cooperativos para lidar com as consequências derivadas desse fenômeno natural.

Um exemplo disso é o Plano de Ação Climática (PAC), construído de forma conjunta entre as cidades de Oakland Park e Wilton Manors no estado da Flórida, nos Estados Unidos. Aprovado em 2019, tem como principais objetivos mitigar os efeitos da mudança climática, reduzindo as emissões de GEE em 1\% a cada ano até 2028 e aumentar a resiliência das comunidades, minimizando os impactos na eficiência e nas operações comerciais de baixo custo (Oakland Park e Wilton Manors, 2019).

O PAC está composto por sete diferentes objetivos, cada um com suas próprias metas, algumas das quais se destacam na seguinte tabela:

\begin{tabular}{|l|l|l|l|}
\hline \multicolumn{1}{|c|}{ Tema } & \multicolumn{2}{|c|}{ Objetivo } & \multicolumn{2}{c|}{ Metas e/ou medidas } \\
\hline Comunidades & Adaptar-se aos impactos das & - Incorporar o aumento do nível do mar nos planos \\
sustentáveis & alterações climáticas e reduzir & urbanos. \\
e transporte & as emissões de GEE, & - Incluir projeções do nível do mar nos mapas das cidades. \\
& reformulando onde e & - Incorporar estratégias de redução de risco no \\
& como construir e mover de um & planejamento & \\
& lugar para outro. & - Adotar padrões de construção ecológicos. \\
& & - Preservar recursos históricos e arqueológicos. \\
\hline
\end{tabular}




\begin{tabular}{|c|c|c|}
\hline & & $\begin{array}{l}\text { - Obter um desenvolvimento baseado no planejamento do } \\
\text { transporte. } \\
\text { - Projetar sistemas de transporte sustentável e equitativos. } \\
\text { - Utilizar as propriedades não utilizadas ou subutilizadas. } \\
\text { - Promover o plantio e manutenção de árvores. } \\
\text { - Eliminar os sistemas sépticos. } \\
\text { - Aumentar o uso de transporte multimodal e promover } \\
\text { instalações para bicicletas e pedestres. }\end{array}$ \\
\hline $\begin{array}{l}\text { Água, esgoto } \\
\text { e } \\
\text { tempestades. }\end{array}$ & $\begin{array}{l}\text { Avançar nas estratégias de } \\
\text { gestão da água e melhorias de } \\
\text { infraestrutura necessárias, em } \\
\text { paralelo com } \\
\text { esforços de conservação da } \\
\text { água existente, para mitigar os } \\
\text { potenciais impactos adversos } \\
\text { das alterações climáticas e do } \\
\text { aumento do nível do mar. }\end{array}$ & $\begin{array}{l}\text { - Promover a gestão inovadora da água. } \\
\text { - Garantir consistência no planejamento dos recursos } \\
\text { hídricos. } \\
\text { - Planejar o futuro abastecimento de água. } \\
\text { - Modernizar os padrões da água. } \\
\text { - Criar sistemas resilientes de controle de inundações. } \\
\text { - Integrar os impactos das águas superficiais e subterrâneas } \\
\text { planejamento. } \\
\text { - Melhorar as práticas de gerenciamento de águas pluviais. } \\
\text { - Incentivar a infraestrutura verde. } \\
\text { - Melhorar as práticas de gestão de águas pluviais. } \\
\text { - Incentivar o financiamento de projetos de gestão de água } \\
\text { baseados na adaptação as mudanças climáticas. } \\
\text { - Apoiar a expansão do armazenamento da água de } \\
\text { superfície. }\end{array}$ \\
\hline $\begin{array}{l}\text { Sistemas } \\
\text { naturais. }\end{array}$ & $\begin{array}{l}\text { Implementar programas de } \\
\text { monitoramento, manejo e } \\
\text { conservação projetados para } \\
\text { proteger os sistemas naturais e } \\
\text { os serviços que prestam à } \\
\text { sociedade. }\end{array}$ & $\begin{array}{l}\text { - Promover a conscientização pública. } \\
\text { - Avaliar impactos de espécies invasoras. } \\
\text { - Procurar financiamento de ciência climática do governo. }\end{array}$ \\
\hline $\begin{array}{l}\text { Energia } \mathrm{e} \\
\text { combustível. }\end{array}$ & 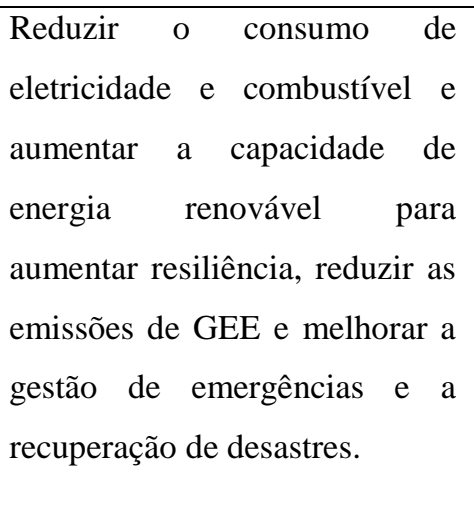 & $\begin{array}{l}\text { - Promover políticas e tecnologia de energias renováveis. } \\
\text { - Avançar na eficiência e conservação de energia. } \\
\text { - Aumentar o acesso à eficiência energética. } \\
\text { - Simplificar os processos de licenciamento } \\
\text { administrativo. } \\
\text { - Ajudar aos proprietários a investir em energias } \\
\text { renováveis. } \\
\text { - Construir capacidade de energia futura. } \\
\text { - Promover o uso de veículos com baixo consumo de }\end{array}$ \\
\hline
\end{tabular}




\begin{tabular}{|c|c|c|}
\hline & & combu \\
\hline $\begin{array}{l}\text { Redução de } \\
\text { riscos } \\
\text { gestão de } \\
\text { emergências. }\end{array}$ & $\begin{array}{l}\text { Preparar as cidades para os } \\
\text { inevitáveis impactos e tensões } \\
\text { experimentados no sudeste da } \\
\text { Flórida através de redução } \\
\text { interdisciplinar de riscos e } \\
\text { planejamento e investimento } \\
\text { em gestão de emergências. }\end{array}$ & $\begin{array}{l}\text { - Identificar populações e infraestrutura em risco. } \\
\text { - Integrar cenários climáticos no planejamento- } \\
\text { - Incluir análises de vulnerabilidade na gestão de } \\
\text { emergências. } \\
\text { - Criar planos de mitigação de desastres. } \\
\text { - Reduzir a exposição ao risco através de seguros. } \\
\text { - Comunicar os riscos a todos os residentes. } \\
\text { - Promover políticas para reduzir os riscos de inundação. } \\
\text { - Incentivar planos de recuperação e adaptação. } \\
\text { - Apoiar o planejamento de desastre e treinamento de } \\
\text { preparação para emergências dos cidadãos. }\end{array}$ \\
\hline $\begin{array}{l}\text { Defesa da } \\
\text { política } \\
\text { pública. }\end{array}$ & $\begin{array}{l}\text { Orientar e influenciar todos os } \\
\text { níveis de governo para lidar } \\
\text { com a mudança climática em } \\
\text { políticas, programas e } \\
\text { legislação. }\end{array}$ & $\begin{array}{l}\text { - Incluir os objetivos do Plano Regional de Ação Climática } \\
\text { (PACR) no planejamento e políticas das cidades. } \\
\text { - Promover a equidade social e econômica. } \\
\text { - Incentivar a participação do público. }\end{array}$ \\
\hline $\begin{array}{l}\text { Estratégia e } \\
\text { engajamento } \\
\text { público. }\end{array}$ & $\begin{array}{l}\text { Conscientizar o público sobre } \\
\text { os riscos relacionados ao clima } \\
\text { que o Sudeste da Flórida } \\
\text { enfrenta e as ações coordenadas } \\
\text { e previas para lidar com esses } \\
\text { riscos. }\end{array}$ & $\begin{array}{l}\text { - Avaliar as necessidades da comunidade para orientar as } \\
\text { comunicações. } \\
\text { - Promover a conscientização e compreensão dos impactos } \\
\text { climáticos por parte da população e as ações pessoais e } \\
\text { opções de políticas públicas disponíveis para responder às } \\
\text { Mudanças climáticas. }\end{array}$ \\
\hline
\end{tabular}

Elaboração própria baseado no conteúdo do PAC (OAKLAND PARK e WILTON MANORS, 2019.)

Certamente, esse plano conjunto é sem dúvida exemplo de boa governança ambiental promovido por cidades vizinhas que, aproveitando essa integração, decidiram estabelecer objetivos comuns em prol da melhoria dos indicadores ambientais e assim contribuir no cumprimento das metas fixadas a nível estadual, federal e global, estratégia de planejamento ambiental interessante pela evidente visão contrária que hoje expressa o governo federal dos Estados Unidos sobre a matéria.

Um outro exemplo deste tipo de ações das cidades em face das mudanças climáticas é o denominado “Green New Deal” ou "OneNYC 2050" da cidade de Nova York, estratégia que tem como meta até 2050 garantir o futuro da cidade com ações ousadas para enfrentar a crise climática, alcançar a equidade e fortalecer a democracia (NEW YORK CITY, 2019), 
agrupadas em 8 objetivos e 30 iniciativas, sendo um desse objetivos dedicado especialmente à temática ambiental, cujas metas serão expostas na seguinte tabela:

\begin{tabular}{|c|c|c|}
\hline \multicolumn{3}{|c|}{ UM CLIMA HABITÁVEL } \\
\hline \multicolumn{3}{|c|}{ Alcançar a neutralidade do carbono e $100 \%$ de eletricidade limpa. } \\
\hline \multicolumn{3}{|c|}{ Fortalecer as comunidades, edifícios, infraestrutura e a orla para ser mais resilientes. } \\
\hline \multicolumn{3}{|c|}{ Criar oportunidades econômicas para todos os nova-iorquinos por meio da ação climática. } \\
\hline \multicolumn{3}{|l|}{ Lutar pela responsabilidade e justiça do clima. } \\
\hline Indicadores & Última medição & Meta \\
\hline $\begin{array}{l}\text { Emissões de GEE eliminadas, reduzidas ou } \\
\text { compensadas. }\end{array}$ & $17 \%(2017)$ & $100 \%$ para o ano 2050. \\
\hline $\begin{array}{l}\text { Misturar o sistema elétrico com fontes } \\
\text { limpas. }\end{array}$ & $27 \%(2019)$ & $100 \%$ para o ano 2040. \\
\hline Inscrições de seguro de inundação. & $35.494(2019)$ & Aumentar. \\
\hline $\begin{array}{l}\text { Investimentos do fundo de pensão da cidade } \\
\text { em soluções para as mudanças climáticas. }\end{array}$ & \$2 bilhões USD (2019) & $\begin{array}{l}\text { Aumentar até } \$ 4 \text { bilhões } \\
\text { USD para o ano } 2021 \text {. }\end{array}$ \\
\hline
\end{tabular}

Elaboração própria baseada no OneNYC 2050 (NEW YORK CITY, 2019)

Além das anteriores medidas ambientais existem outras estratégias que ajudam igualmente na melhoria do meio ambiente da cidade e o cumprimento dos indicadores, como são a promoção de opções de transporte sustentáveis, a adoção de um plano de gestão de resíduos sob a política "lixo zero" e o apoio na implantação de estilos de vida sustentáveis nos cidadãos, baseados em políticas educativas que permitam entre outras coisas uma redução no consumo de alimentos processados e carne bovina (NEW YORK CITY, 2019).

O caso de Nova York apresenta um modelo que, além de ambicioso, está ligado de forma direta à GAG, já que foi a primeira cidade em basear sua estratégia local nos ODS da “Agenda 2030” e enviá-la voluntariamente para revisão por parte das Nações Unidas, em atividade onde são identificadas as diferentes opções de melhora derivadas de outras experiências promovidas em outros lugares (NEW YORK CITY, 2019 p. 51).

\section{Conclusões}

A governança global entendia como modelo de articulação e cooperação entre diferentes atores do cenário internacional, além dos tradicionais sujeitos das relações internacionais (Estados e organizações internacionais), permite adotar decisões aos diferentes 
problemas comuns entre eles. Nesse sentido, faz-se referência a um processo de discussão global abrangente no qual existe participação de ONG's, governos subnacionais, empresas multinacionais, cidades e sociedade civil, entre outros.

Assim, as problemáticas ambientais atuais são um cenário ótimo para o estabelecimento de um sistema de governança, em razão da interdependência existente entre as diferentes nações para lidar com essas questões, porque da boa qualidade do meio ambiente mundial dependem a subsistência dos países e a sobrevivência das diferentes espécies de seres vivos, incluído o homem. Esse sistema chamado GAG é muito importante diante das mudanças climáticas, cuja existência e avanço fazem necessária a adoção de estratégias articuladas para seu combate e adaptação.

Por isso, as cidades hoje em dia têm papel importante nas discussões ambientais globais e para desenvolver políticas e planos ambientais, ainda mais quando é nelas que grande parte dos GEE são produzidos, sendo eles uma das causas das citadas mudanças climáticas e assim uma questão estratégica para melhorar os indicadores ambientais.

Nesse contexto, planos de ação global a longo prazo como a "Agenda 21" e mais recentemente a "Agenda 2030" aprofundam e reconhecem com clareza o papel destacado que têm as cidade e seus governos no desenvolvimento de estratégias e políticas ambientais, reconhecendo que é em seus territórios que há maior possibilidade de promover planos de ação mais efetivos porquanto estão encarregados da criação, funcionamento e manutenção da infraestrutura econômica, social e ecológica, além de supervisionar o planejamento através de políticas e regulamentações ecológicas locais.

No caso da “Agenda 2030", é importante destacar como os ODS 11 e 13 são dedicados às diferentes atividades que desde as cidades devem-se realizar para tornar os espaços urbanos lugares inclusivos, seguros, resilientes e sustentáveis, assim como cenários de implementação positiva de medidas de mitigação e adaptação aos desafios que representam as mudanças climáticas na atualidade.

Em suma, a GAG hoje está focada na promoção e implementação de ações baseadas numa estratégia bottom-up, apresentando assim uma variedade de desafios de natureza multinível na qual as cidades desenvolvem papel vital para o cumprimento dos diferentes objetivos e metas ambientais que estão fixados em níveis regionais, nacionais e globais, sendo este um modelo diferenciado daquele que era desenvolvido nos sistemas de governança tradicional baseados na burocracia, hierarquização e respostas tardias. 
Em conformidade, as cidades hoje participam das discussões ambientais globais de forma organizada e não isolada, sendo sua principal estratégia a criação de redes de política que garantem uma atuação cooperativa partindo da partilha de experiências desenvolvidas pelas cidades em seus territórios, tão como acontece com o ICLEI, C40, o Plano de Autarcas para o Clima e Energia e a Rede de cidades BID, entre outras mais.

Além disso e produto das debilidades da tradicional forma de tratar as relações internacionais, onde só participam os Estados-nação e as organizações internacionais, os sistemas de governança permitiram a participação nas discussões internacionais de atores como as cidades, cuja importância e organização podem levar até a terem sua própria politica externa sem ajuda dos governos centrais, que é conhecido como paradiplomacia.

Nesse sentido, a existência de esses cenários de encontro entre as cidades permite o surgimento de planos de ação ambiental em diferentes cidades, sendo alguns exemplos desses, o plano ambiental conjunto de Oakland Park e Wilton Manors nos Estados Unidos e o planos de ação ambiental estabelecido recentemente na cidade de Nova York, esse último reconhecido como "Green New Deal".

O caso de Nova Iorque merece especial atenção dada sua relação direta com a GAG, já que foi a primeira cidade a basear sua estratégia local nos ODS da “Agenda 2030" e enviá-la voluntariamente para revisão por parte das Nações Unidas, prova do engajamento das cidades nas discussões ambientais globais.

\section{Referências.}

BARBI, Fabiana. Mudanças Climáticas e respostas políticas nas cidades. Campinas (SP): Editora Unicamp, 2015.

BECK, Ulrich. A Metamorfose do Mundo: Como as alterações climáticas estão a transformar a sociedade. Lisboa: Edições 70, 2016.

BEYERLIN, Ulrich; MARAUHN, Thilo. International Environmental Law. Oxford, UK: Hart Publishing, 2011.

COMISSÃO SOBRE GOVERNANÇA GLOBAL. Nossa Comunidade Global. Rio de Janeiro: Editora Fundação Getúlio Vargas, 1996.

ESTY, Daniel C.; IVANOVA, Maria H. O Caminho Futuro: Conclusões e agenda de ações. Em: ESTY, Daniel C.; IVANOVA, Maria H. (Orgs.) Governança Ambiental Global: Opções e Oportunidades. São Paulo: Editora Senac São Paulo, 2005. 
GONÇALVES, Alcindo; COSTA, José Augusto Fontoura. Governança Global e Regimes Internacionais. São Paulo: Almedina, 2011.

IVANOVA, Maria. "O PNUMA e a Governança Ambiental Global”. Em: CADERNOS ADENAUER. Governança Global. Ano IX, n. 3. Rio de Janeiro: Fundação Konrad Adenauer, 2009.

KOTZIAS, Fernanda Vieira; SILVEIRA, Henrique Lago da. Contribuições da Paradiplomacia para a Agenda Ambiental da Governança Global: Aspectos teóricos e práticos. Em: GONÇALVES, Alcindo; REI, Fernando. (Orgs.) Governança e Paradiplomacia Ambiental. Santos: Editora Universitária Leopoldianum, 2015.

LORENZETTI, Julia Vaz; CARRION, Rosinha Machado. Governança Ambiental Global: Atores e cenários. Rio de Janeiro: Revista Cadernos EBAPE.BR vol.10 no.3, 2012. Disponível em: <http://www.scielo.br/pdf/cebape/v10n3/14.pdf> Acesso em: 10 jun. 2019.

MACEDO, Laura Valente de; SETZER Joana. O Papel dos Governos Locais e o Caso do Município de São Paulo. Em: GRANZIERA, Maria Luiza Machado; REI, Fernando (Org.) O Futuro do Regime Internacional das Mudanças Climáticas: Aspectos Jurídicos e Institucionais. Santos (SP): Editalivros Produções Editoriais, 2015

MARTINS, Rafael D'Almeida; FERREIRA, Leila da Costa. Uma revisão crítica sobre cidades e mudança climática: vinho velho em garrafa nova ou um novo paradigma de ação para a governança local? Rio de Janeiro: Revista de Administração Pública - RAP da Escola Brasileira de Administração Pública e de Empresas, vol. 45 no. 3, 2011. Disponível em: <https://www.redalyc.org/pdf/2410/241019893004.pdf> Acesso em: 13 ago. 2019.

MEADOWS, Dennis L. et al. The Limits of Growth: A reporter for The Club Rome's Project on the Predicament of Mankind. New York: Universe Books, 1972. Disponível em: <http://www.donellameadows.org/wp-content/userfiles/Limits-to-Growth-digital-scanversion.pdf> Acesso em: 10 jun. 2019.

NASSER, Salem H. Fontes e Normas do Direito Internacional. Um estudo sobre a soft law. São Paulo: Atlas, 2 ed., 2006.

NEW YORK CITY. OneNYC 2050 Building a strong and fair city. A livable climate. 2019. Disponível em: <https://onenyc.cityofnewyork.us/wpcontent/uploads/2019/05/OneNYC-2050-A-Livable-Climate.pdf> Acesso em 19. Ago. 2019.

O'BRIEN, Robert et al. Contesting global Governance: Multilateral Economic and Global Social Movements. Cambridge (UK): Cambridge University Press, 2000.

OAKLAND PARK E WILTON MANORS. Two cities. One sustainable future. Climate Action Plan. 2019. Disponível em: $<$ https://www.wiltonmanors.com/DocumentCenter/View/4747/OP-WM-Climate-ActionPlan-FINAL-February-2019> Acesso em: 18 ago. 2019. 
ONU. $\quad$ Agenda 1992 Disponível em: <https://sustainabledevelopment.un.org/content/documents/Agenda21.pdf> Acesso em: 24 mai. 2019.

Disponível

Informe de la Comisión Mundial sobre el Medio Ambiente y el Desarrollo. 1987. <http://www.ecominga.uqam.ca/PDF/BIBLIOGRAPHIE/GUIDE_LECTURE_1/CMMADInforme-Comision-Brundtland-sobre-Medio-Ambiente-Desarrollo.pdf $>$ Acesso em: 10 jun. 2019.

Protocolo de Kyoto de la Convención Marco de las Naciones Unidas sobre el Cambio Climático. $1998 . \quad$ Disponível em: <https://unfccc.int/resource/docs/convkp/kpspan.pdf > Acesso em: 18 set. 2019.

Transformando Nosso Mundo: A Agenda 2030 para o Desenvolvimento Sustentável. Nova Iorque, 2015. Disponível em: <https://nacoesunidas.org/wpcontent/uploads/2015/10/agenda2030-pt-br.pdf> Acesso em: 10 jun. 2019.

REI, Fernando. International Environmental Law: New Approaches. Em: MALICK, Tafsir; MORE, Rodrigo Fernandes. (Ed.). Prospects of Evolution of the Law of the Sea, Environmental Law and the Practice of ITLOS: New Challenges and Emerging Regimes. Rio de Janeiro: SAGSERV, 2018.

REI, Fernando; GONÇALVES, Alcindo; SOUZA, Luciano. Acordo de Paris: Reflexões e Desafios para o Regime Internacional das Mudanças Climáticas. Belo Horizonte: Revista Veredas do Direito. v.14. n.29. p.81-99 Mai./Ago. de 2017. Disponível em: <https://bdjur.stj.jus.br/jspui/bitstream/2011/121676/acordo_paris_reflexoes_rei.pdf> Acesso em: 22 mai. 2019

REI, Fernando; GRANZIERA, Maria Luiza Machado. Direito Ambiental Internacional: Novos olhares para a ciência do direito. Em: GRANZIERA, Maria Luiza Machado; REI, Fernando (Coord.). Direito Ambiental Internacional: Avanços e Retrocessos. 40 Anos de Conferências das Nações Unidas. São Paulo: Editora Atlas S.A., 2015.

SATTERTHWAITE, David. Cities' contribution to global warming: Notes on the allocation of greenhouse gas emissions. London: Environment \& Urbanization Journal: International Institute for Environment and Development (IIED). v. 20 n. 2 pp. 539-549. 2008. Disponível em: <https://doi.org/10.1177/0956247808096127> Acesso em: 22 mai. 2019

SCHMIDT, Luísa; GUERRA, João. Da Governança Global à Sustentabilidade Local: Portugal e o Brasil em Perspectiva Comparada. Fortaleza: Revista de Ciências Sociais da Universidade Federal de Ceará - UFC. v. 41 n. 2, 2010. Disponível em: <https://repositorio.ul.pt/bitstream/10451/20350/1/ICS_LSchmidt_JGuerra_Governanca_ARI .pdf> Acesso em: 13 ago. 2019

SETTE, Ana Tarsilia de Miranda e Sousa. Governança global e redes globais de políticas públicas: atores brasileiros no cenário das mudanças climáticas. Dissertação (Mestrado 
em Administração Pública)-Fundação Getúlio Vargas FGV, Rio de Janeiro, 2010. Disponível em:

<http://bibliotecadigital.fgv.br/dspace/bitstream/handle/10438/7825/Ana\%20Tarsila.pdf?sequ ence=1\&isAllowed=y $>$ Acesso em: 15 ago. 2019

SPETH, James Gustave. A agenda ambiental global: origens e perspectivas. Em: ESTY, Daniel C.; IVANOVA, Maria H. (Orgs.) Governança Ambiental Global: Opções e Oportunidades. São Paulo: Editora Senac São Paulo, 2005.

STRECK, Charlotte. Redes globais de políticas públicas como coalizões para mudança. Em: ESTY, Daniel C.; IVANOVA, Maria H. (Orgs.) Governança Ambiental Global: Opções e Oportunidades. São Paulo: Editora Senac São Paulo, 2005. 